\title{
On the production of ${ }^{52 \mathrm{~g}} \mathrm{Mn}$ by deuteron irradiation on natural chromium and its radionuclidic purity
}

\author{
Francesca Bianchi $^{\mathrm{a}, \mathrm{b}}$, Claudio Marchi ${ }^{\mathrm{c}}$, Glara Fuad ${ }^{\mathrm{d}, \mathrm{a}, \mathrm{b}}$, Flavia Groppi $^{\mathrm{a}, \mathrm{b}}$, \\ Férid Haddad $^{\mathrm{e}, \mathrm{f}}$, Luca Magagnin ${ }^{\mathrm{c}}$, Simone Manenti ${ }^{\mathrm{a}, \mathrm{b}, *}$ \\ ${ }^{a}$ Department of Physics, Università degli Studi di Milano, via Celoria 16, I-20133 Milano, \\ Italy \\ ${ }^{b}$ LASA, Department of Physics, Università degli Studi di Milano and INFN-Milano, via \\ F.lli Cervi 201, I-20090 Segrate (MI), Italy \\ ${ }^{c}$ Department of Chemistry, Materials and Chemical Engineering "Giulio Natta", Politecnico \\ di Milano, via Mancinelli 7, I-20131 Milano, Italy \\ ${ }^{d}$ Physics Department, Salahaddin University, Kirkuk Road, IQ-44001 Erbil, Iraq \\ ${ }^{e} S U B A T E C H$, Institut Mines Telecom Atlantique, CNRS/IN2P3, Nantes, Université de \\ Nantes France \\ ${ }^{f}$ GIP Arronax, 1 rue Aronnax, 44817-CEDEX Saint-Herblain, France
}

\begin{abstract}
The positron emitter ${ }^{52 \mathrm{~g}} \mathrm{Mn}$ is used for the Positron Emission Tomography PET imaging and, exploiting its paramagnetic property, it can also be used in Manganese-Enhanced Magnetic Resonance imaging in PET/MEMRI dual modality. In this work we investigate the nuclear reactions for production of ${ }^{52 \mathrm{~g}} \mathrm{Mn}$ and ${ }^{54} \mathrm{Mn}$ induced by deuteron beams on natural chromium targets at energies up to $\mathrm{E}_{d}=28 \mathrm{MeV}$ using the stacked-foils activation technique. We calculate the Thick Target Yields for ${ }^{52 \mathrm{~g}} \mathrm{Mn}$ and for the radionuclidic impurity ${ }^{54} \mathrm{Mn}$, and we compare the Radionuclidic Purity of ${ }^{52 \mathrm{~g}} \mathrm{Mn}$ with the results obtainable by proton irradiations. The cross-sections of the reactions ${ }^{\text {nat }} \mathrm{Cr}(\mathrm{d}, \mathrm{pxn}){ }^{51} \mathrm{Cr}$ and
\end{abstract} ${ }^{\text {nat }} \mathrm{Cr}(\mathrm{d}, \mathrm{x}){ }^{48} \mathrm{~V}$ are also presented.

Keywords: manganese-52, chromium target, deuteron particle irradiation, cross-section, yield, Mn radioisotopes

\footnotetext{
${ }^{*}$ Corresponding author +390250319528

Email address: simone.manenti@mi.infn.it (Simone Manenti)
} 


\section{Introduction}

Manganese- $52\left({ }^{52 g} \mathrm{Mn}\right)$ is a radionuclide that decays by positron emission and electron capture (EC), with a medium-long half-life $\left(\mathrm{t}_{1 / 2}=5.591 \mathrm{~d}[1]\right)$. It has also a metastable level $\left({ }^{52 \mathrm{~m}} \mathrm{Mn}-\mathrm{t}_{1 / 2}=21.1 \mathrm{~m}\right)$, that decays by isomeric

5 transition (IT) on the ground level $(1.68 \%-377.748 \mathrm{keV})$. As a positron emitter, ${ }^{52 \mathrm{~g}} \mathrm{Mn}$ can be used in Positron Emission Tomography - PET imaging to study biological and physiological processes on the same time scale of its decay. The energy of emitted positrons $\left(<\mathrm{E}>_{\beta^{+}}=244.6 \mathrm{keV} ; \mathrm{I}_{\beta^{+}}=29 \%[2,3\right.$, 4]) corresponds to a range in tissue of $0.63 \mathrm{~mm}$ : these quantities are comparable with those of fluorine-18 ( ${ }^{18} \mathrm{~F}-252 \mathrm{keV} ; 97 \%$; $0.66 \mathrm{~mm}$ ) and, therefore, it would be possible to obtain diagnostic images of similar intrinsic spatial resolution [4. Furthermore many studies, more or less recent, suggest different possible areas of application of radioactive manganese in medicine, such as bone scintigraphy [5], myocardial perfusion imaging [6], study of diabetes progression [7, 15 in-vivo tracking of stem cells [8] and immunoPET [9]. Thanks to its paramagnetic property, ${ }^{52 \mathrm{~g}} \mathrm{Mn}$ can also be used in Manganese-Enhanced Magnetic Resonance Imaging - MEMRI in combination with PET, opening to the possibility of obtaining multi-modal PET/MEMRI images in order to obtain specific and complementary diagnostic information [10, 11, 12.

20

${ }^{52 \mathrm{~g}} \mathrm{Mn}$ can be produced by cyclotron with proton or deuteron beams, mainly exploiting $(\mathrm{p}, \mathrm{xn})$ and $(\mathrm{d}, \mathrm{xn})$ reactions on natural chromium targets $\left({ }^{50} \mathrm{Cr}: 4.345 \%\right.$; $\left.{ }^{52} \mathrm{Cr}: 83.789 \% ;{ }^{53} \mathrm{Cr}: 9.501 \% ;{ }^{54} \mathrm{Cr}: 2.365 \%\right)$, but also by $(\mathrm{p}, \alpha \mathrm{n}),\left(\mathrm{p},{ }^{3} \mathrm{He}\right)$, $(\mathrm{d}, \alpha 2 \mathrm{n})$ and $(\mathrm{d}, \alpha)$ reactions on iron targets.

${ }_{25}$ Production with protons on chromium targets has already been extensively studied [13, 14]: for ${ }^{\text {nat }} \mathrm{Cr}(\mathrm{p}, \mathrm{xn})$ reaction ${ }^{52 \mathrm{~g}} \mathrm{Mn}$ is obtained with a Thick Target Yield (TTY) of $3.89 \mathrm{GBq} \cdot \mathrm{C}^{-1}$, when considering an incident beam energy of $17 \mathrm{MeV}$ and a target thickness of $\Delta \mathrm{E}=9 \mathrm{MeV}$, leading to an output proton energy of $8 \mathrm{MeV}$ [15]. The use of deuteron beams could be a good alternative and may even be more advantageous in terms of higher yield, specific activity 
and chemical purity. It is therefore necessary to know accurately the excitation function of nat $\mathrm{Cr}(\mathrm{d}, \mathrm{xn}){ }^{52 \mathrm{~g}} \mathrm{Mn}$ reaction and expand the energy range beyond the maximum $(\mathrm{E} \sim 21 \mathrm{MeV})$, as deuteron reactions often lead to a broader peak than proton ones, which converts into a higher yield: currently the data published in

35 literature are generally quite dated and scarce at high energy; furthermore the two most recent works report conflicting values for the cross-section values [16, 17. In this work, in order to enrich and improve available data, the excitation function and the yield for ${ }^{\text {nat }} \mathrm{Cr}(\mathrm{d}, \mathrm{xn}){ }^{52 \mathrm{~g}} \mathrm{Mn}$ reaction were determined in the 8-28 MeV energy range: experimental results are reported and compared with

4o experimental data available in literature [16, 17, 18, 19, 20, 21, 22, 23, 24, 25]. At the same time we evaluated the cross-section also for ${ }^{54} \mathrm{Mn},{ }^{51} \mathrm{Cr}$ and ${ }^{48} \mathrm{~V}$, co-produced by the reaction ${ }^{n a t} \mathrm{Cr}(\mathrm{d}, \mathrm{x})$. Due to its long half-life, it was not possible to determine the cross-section for the production of ${ }^{53} \mathrm{Mn}$ and we have considered this isotope as stable.

\section{2. Experimental}

The excitation functions were determined by using the stacked-foils technique. Four stacks have been prepared in two different configurations, each of them containing four ${ }^{\text {nat }} \mathrm{Cr}$ targets: in the first two, after a $\mathrm{Cr}$ target, natural aluminium and titanium foils were placed as respectively degrader and monitor

so foils. In the remaining stacks, in addition to $\mathrm{Al}$ and $\mathrm{Ti}$ foils, natural iridium targets were inserted in order to take advantage of energy degradation to simultaneously study other cross-sections for the production of other radionuclides of interest in Nuclear Medicine applications.

\section{Target preparation}

${ }^{\text {nat }} \mathrm{Cr}$ foils were prepared by the Department of Chemistry, Materials and Chemical Engineering "Giulio Natta" of Milan Polytechnic, by electro-deposition technique on $16 \mu \mathrm{m}$ thick aluminum foils. The chromium coating on Al foil was obtained through a multi-step electrochemical process. Firstly, the ac- 
tive area of the $\mathrm{Al}$ substrate was selected by masking the $\mathrm{Al}$ foil with a $3 \mathrm{D}$ printed polypropylene mask also acting as mechanical support. Such masking system was designed to overcome the high flexibility of the foil, which, otherwise, couldn't remain in a fixed position within the deposition bath (Fig. 17). The electrical contact to the $\mathrm{Al}$ foil was provided by a $\mathrm{Cu}$ strip and $\mathrm{Cu}$ tape. After the selection of the appropriate area $\left(4 \times 4 \mathrm{~cm}^{2}\right)$ the aluminum substrate was activated by a $0.25 \mathrm{M} \mathrm{NaOH}$ solution to remove superficial oxides and clean the surface for an optimal deposition process. Due to acidity of the chromium deposition bath and to the difference in relative nobility between $\mathrm{Al}$ and $\mathrm{Cr}$, in order to obtain a good chromium coating, an intermediate Zn layer is required. The zinc layer was applied to the activated surface through a galvanic 7o displacement deposition process: the masked Al foil was immersed in the $\mathrm{Zn}$ electrolyte to produce a compact dark grey coating. The zinc deposition bath consists of sodium hydroxide $\mathrm{NaOH} 3.28 \mathrm{M}$ and zinc oxide $\mathrm{ZnO} 0.3 \mathrm{M}$. The $\mathrm{Zn}$ layer after the deposition process was most of the time non-measurable due to the extremely small thickness $(<5 \mathrm{~nm})$ and the signal of $\mathrm{Zn}$ was not present in the XRF analysis: therefore we neglected the zinc layer in the calculation of the beam energy loss. The $\mathrm{Zn}$ deposition process was conducted at room temperature for 1 minute after the onset on $\mathrm{H}_{2}$ bubbles from the $\mathrm{Al}$ surface. Upon extraction, the $\mathrm{Al}$ substrate was quickly rinsed with water to prevent the displacement reaction to continue and subsequently etched in $\mathrm{HNO}_{3}(5 \% \mathrm{w} / \mathrm{v})$.

so A second $\mathrm{Zn}$ deposition, with the same parameters, was performed to improve the compactness and adhesion of the zinc layer to the aluminum foil. The $\mathrm{Al} / \mathrm{Zn}$ substrate was then immersed in a standard aqueous chromium deposition bath, with the following composition: $2.5 \mathrm{M} \mathrm{CrO}_{3}, 25.5 \mathrm{mM} \mathrm{H}_{2} \mathrm{SO}_{4}$. The chromium oxide is dissolved in the plating solution providing $\mathrm{Cr}$ ions, so the deposit doesn't 85 contain any oxides because the deposition involves the reduction of ions to their zero-valent (metallic) state. The setup consisted in a standard electrodeposition cell, with the $\mathrm{Al} / \mathrm{Zn}$ foil as the cathode and a $\mathrm{Pb}$ strip as anode, both connected to a power supply system (Fig. 1b): the process is conducted in current control, with a standard galvanostat/potentiostat. Lead was chosen as preferential ma- 


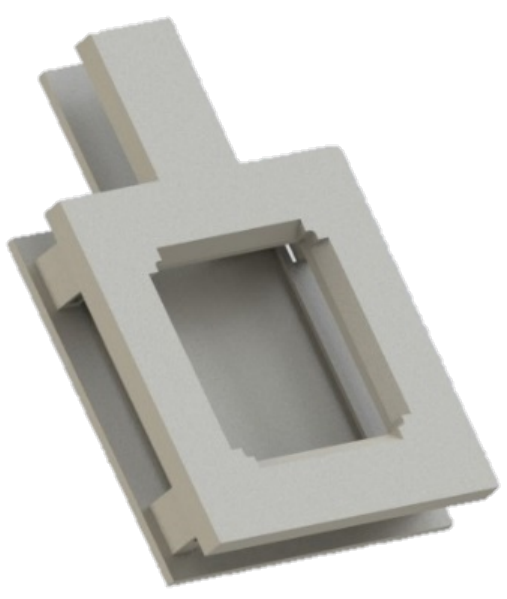

(a)

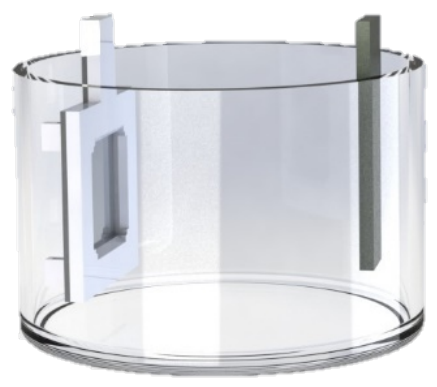

(b)

Figure 1: (a) 3D-printed polypropylene mask used as mechanical support of Al foils and to overcome the high flexibility of the foils, taking them in a fixed position within the deposition bath and (b) setup for the electro-deposition with $\mathrm{Al} / \mathrm{Zn}$ foil as the cathode and a $\mathrm{Pb}$ strip as anode.

terial for the anode due to its known ability to passivate in presence of $\mathrm{Cr}$ and form a superficial homogeneous layer of $\mathrm{PbCrO}_{4}$, lead chromate. The presence of the lead chromate is important for the chemical stability of the solution and the overall electro-deposition process, since its presence provides a very chemically stable layer on the anode which becomes chemically inert and allows for 95 a stable voltage output and for a reproducible and controllable plating process. In order to avoid the dissolution of the $\mathrm{Al} / \mathrm{Zn}$ substrate, the insertion in the deposition bath was performed in cathodic protection, i.e. applying current to the system before immersion, thus avoiding corrosion of the cathode. The electro-deposition process was performed at $55^{\circ} \mathrm{C}$, supplying a current density of $75 \mathrm{~mA} \cdot \mathrm{cm}^{-2}$ for 210 minutes. The deposited $\mathrm{Cr}$ film had an average thickness of about $20 \mu \mathrm{m}$, resulting in a growing rate of $\sim 95 \mathrm{~nm} \cdot \mathrm{min}^{-1}$ that is in line with the industrial process.

From the various metal foils, squares were cut out with $2.5 \times 2.5 \mathrm{~cm}^{2}$ dimensions in order to be fixed in the suitable holder for the irradiation. 
The titanium (purity 99.6\%, $20 \mu \mathrm{m}$ ), aluminum (purity 99.999\%, $16 \mu \mathrm{m}$ and $50 \mu \mathrm{m}$ ) and iridium (purity 99.9\%,25 $\mu \mathrm{m}$ ) foils were purchased by Goodfellow Corporation. For each foil the uniformity was verified with an analogical specimeter and the effective thickness was determined by measuring the mass (Ti: $8.1 \mathrm{mg} \cdot \mathrm{cm}^{-2}$; Al: $4.3 \mathrm{mg} \cdot \mathrm{cm}^{-2}$ and $13.4 \mathrm{mg} \cdot \mathrm{cm}^{-2}$; Ir: $55.9 \mathrm{mg} \cdot \mathrm{cm}^{-2}$ and $56.9 \mathrm{mg} \cdot \mathrm{cm}^{-2}$ ); the chromium targets were measured individually, obtaining a mass thickness value in the range $10.5-17.0 \mathrm{mg} \cdot \mathrm{cm}^{-2}$.

\section{Irradiation conditions}

The irradiations were carried out by accelerating deuterons with the high intensity and high energy cyclotron (AVF IBA-C70XP, $\mathrm{K}=70$ ) of ARRONAX research center in Saint-Herblain (FR) [26]. Four irradiations with different incident beam energies were performed on a total of 16 natural chromium targets, covering the energy range between 8 and $28 \mathrm{MeV}$ with an interval of about 1 $\mathrm{MeV}$, with a constant current of about $150 \mathrm{nA}$ for a duration of $1 \mathrm{~h}$; the intensity and energy of the beam were verified by comparing our experimental cross-sections of the monitor reactions ${ }^{\text {nat }} \mathrm{Ti}(\mathrm{d}, \mathrm{x})^{48} \mathrm{~V}$ and ${ }^{\text {nat }} \mathrm{Ti}(\mathrm{d}, \mathrm{x})^{46} \mathrm{Sc}$ with IAEA tabulated ones [27] (Fig. 2). The stacks were irradiated in air, positioned at the distance of $6-8 \mathrm{~cm}$ from the end of the beam line, which is closed by a $75 \mu \mathrm{m}$ thick Kapton window. The four irradiations, performed in 2 rounds at 125 6-months laps, led to coherent data proving the quality and reproducibility of the results.

\section{Measurements}

The radioactivity measurements of the targets were performed without any chemical processing at the LASA Laboratory (INFN and Physics Department 130 of University of Milano, Segrate, MI), employing a calibrated high purity germanium (HPGe) detector (EG\&G Ortec, $15 \%$ relative efficiency, FWHM =2.2 $\mathrm{keV}$ at $1.33 \mathrm{MeV}$ ). The measurements started within few days after end of bombardment (EOB) and continued periodically for about $4-5$ months, in order to 


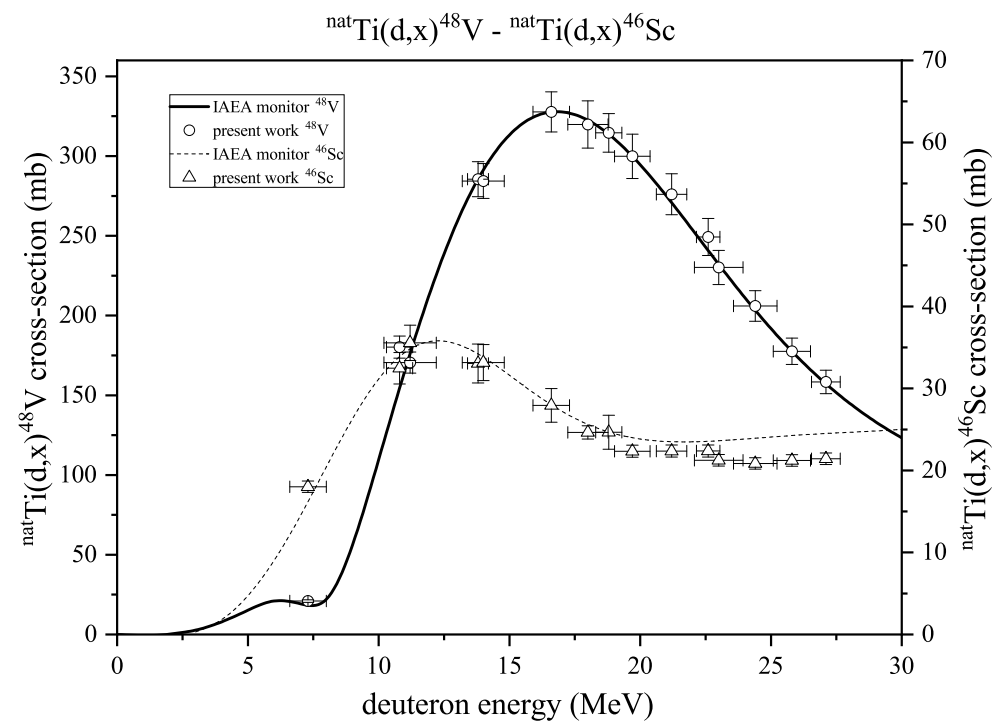

Figure 2: The measured excitation functions for ${ }^{n a t} \mathrm{Ti}(\mathrm{d}, \mathrm{x})^{48} \mathrm{~V}$ and ${ }^{\text {nat }} \mathrm{Ti}(\mathrm{d}, \mathrm{x})^{46} \mathrm{Sc}$ nuclear reactions compared with the IAEA [27] recommended ones.

collect a large number of data to reduce the uncertainties on the quantities of interest, as well as to verify the exponential decrease of nuclide radioactivity in order to identify possible interferences if any. The radionuclides for which the cross-sections were measured are shown in Table 1 with their own decay characteristics, gamma emissions and intensities [1, the contributing reactions for their production and the related threshold energies [28].

\section{Results}

The activity values obtained from gamma spectrometry measurements on each target were used for the calculation of the cross-section $\sigma(\mathrm{E})\left[\mathrm{cm}^{2} \cdot \mathrm{atom}^{-1}\right]$, through the relation:

$$
\sigma(E)=\frac{A \cdot M \cdot Z \cdot e}{\rho x \cdot N_{A} \cdot Q \cdot \lambda} \cdot D(R T) \cdot G\left(t_{i r r}\right) \cdot e^{\lambda \cdot \Delta t}
$$

where $\mathrm{E}[\mathrm{MeV}]$ is the beam energy in the target, $\mathrm{A}[\mathrm{Bq}]$ is the radioactivity of the nuclide of interest, $\mathrm{M}\left[\mathrm{g} \cdot \mathrm{mol}^{-1}\right]$ is the target atomic mass, $\mathrm{Z}$ the 
Table 1: Decay data [1] of $\mathrm{Mn}, \mathrm{Cr}$ and $\mathrm{V}$ radionuclides with the contributing nuclear reactions and the related threshold energies $(\mathrm{MeV})$ [28].

\begin{tabular}{|c|c|c|c|c|c|}
\hline Nuclide & $\mathbf{t}_{1 / 2}$ & $\mathbf{E}_{\gamma}(\mathrm{keV})$ & $\mathbf{I}_{\gamma}(\%)$ & Contributing reactions & $\mathbf{E}_{\text {th }}(\mathrm{MeV})$ \\
\hline \multirow[t]{3}{*}{${ }^{52} \mathrm{~g} \mathrm{Mn}$} & $5.591 \mathrm{~d}$ & 1434.068 & 100 & ${ }^{52} \mathrm{Cr}(\mathrm{d}, 2 \mathrm{n})$ & 8.02 \\
\hline & & 935.538 & 94.5 & ${ }^{53} \mathrm{Cr}(\mathrm{d}, 3 \mathrm{n})$ & 16.25 \\
\hline & & 744.233 & 90.0 & ${ }^{54} \mathrm{Cr}(\mathrm{d}, 4 \mathrm{n})$ & 26.33 \\
\hline \multirow[t]{2}{*}{${ }^{54} \mathrm{Mn}$} & $312.3 \mathrm{~d}$ & 834.848 & 99.976 & ${ }^{53} \mathrm{Cr}(\mathrm{d}, \mathrm{n})$ & 0 \\
\hline & & & & ${ }^{54} \mathrm{Cr}(\mathrm{d}, 2 \mathrm{n})$ & 4.55 \\
\hline \multirow[t]{5}{*}{${ }^{51} \mathrm{Cr}$} & $27.702 \mathrm{~d}$ & 320.0842 & 9.86 & ${ }^{50} \mathrm{Cr}(\mathrm{d}, \mathrm{p})$ & 0 \\
\hline & & & & ${ }^{50} \mathrm{Cr}(\mathrm{d}, \mathrm{n}){ }^{51} \mathrm{Mn} \rightarrow{ }^{51} \mathrm{Cr}$ & 16.25 \\
\hline & & & & ${ }^{52} \mathrm{Cr}(\mathrm{d}, \mathrm{t})$ & 6.01 \\
\hline & & & & ${ }^{53} \mathrm{Cr}(\mathrm{d}, \mathrm{tn})$ & 14.24 \\
\hline & & & & ${ }^{54} \mathrm{Cr}(\mathrm{d}, \mathrm{t} 2 \mathrm{n})$ & 24.32 \\
\hline \multirow[t]{3}{*}{${ }^{48} \mathrm{~V}$} & $15.9735 \mathrm{~d}$ & 983.517 & 99.98 & ${ }^{50} \mathrm{Cr}(\mathrm{d}, \alpha)$ & 0 \\
\hline & & 1312.096 & 97.4805 & ${ }^{52} \mathrm{Cr}(\mathrm{d}, \alpha 2 \mathrm{n})$ & 15.99 \\
\hline & & & & ${ }^{53} \mathrm{Cr}(\mathrm{d}, \alpha 3 \mathrm{n})$ & 24.65 \\
\hline
\end{tabular}


atomic number of the projectile, e $[\mathrm{C}]$ is the electron charge, $\rho \mathrm{x}\left[\mathrm{g} \cdot \mathrm{cm}^{-2}\right]$ the mass thickness of the target, $\mathrm{N}_{\mathrm{A}}\left[\right.$ atom $\cdot \mathrm{mol}^{-1}$ ] is Avogadro's number, $\mathrm{Q}[\mathrm{C}]$ is the integrated deuteron charge, $\lambda\left[\mathrm{s}^{-1}\right]$ the decay constant, and $\Delta \mathrm{t}[\mathrm{s}]$ the waiting time from the EOB. $\mathrm{G}\left(\mathrm{t}_{\mathrm{irr}}\right)$ and $\mathrm{D}(\mathrm{RT})$ are respectively the growing factor and the decay factor, which take into account the decay during irradiation and counting time RT. The error bars were determined taking into account the uncertainties from the different contributions, as reported in Manenti et al. [29. The experimental results for excitation functions obtained in this work are reported in Table 2 and in Fig. 3, 4, 6 and 5, compared with the data published in literature [16, 17, 18, 19, 20, 21, 22, 23, 24, 25]; theoretical predictions, obtained from TENDL 2019 on-line library [30] and from EMPIRE 3.2.2 [31, are also presented for comparison. It is possible to appreciate that some data points for very close energies, corresponding to different stacks, overlap well, thus demonstrating the excellent agreement between the results obtained by the different irradiations. In order to obtain an evaluation of the radionuclidic purity (RNP) for the ${ }^{52 \mathrm{~g}} \mathrm{Mn}$ production, Thick Target Yields (TTY) $\left[\mathrm{Bq} \cdot \mathrm{C}^{-1}\right]$ were determined for ${ }^{52 \mathrm{~g}} \mathrm{Mn}$ and ${ }^{54} \mathrm{Mn}$ (Fig. 7 and 8 using the relationship:

$$
Y(E, \Delta E)=\int_{E-\Delta E}^{E} \frac{\sigma(E) \cdot N_{A} \cdot \lambda}{M \cdot e \cdot \frac{d E}{\rho d x}(E)} d E
$$

where $\Delta \mathrm{E}$ represents the loss of energy in the thick target.

\section{1. ${ }^{\text {nat }} \mathrm{Cr}(d, x n)^{52 g, \text { cum }} \mathrm{Mn}$}

In our experimental conditions it was not possible to measure the contribution of the metastable level $\left(t_{1 / 2}=21.1 \mathrm{~m}\right)$ that decays to the longer lived ground state by IT (1.68\%): the determined cross-section is relative to the cumulative production of ${ }^{52 \mathrm{~g}} \mathrm{Mn}$. The experimental excitation function is reported in Fig. 3 ,

Our data are in agreement with the results of other works for energies up to $20 \mathrm{MeV}$, while for higher energies, where only one set of data exists, they deviate slightly with lower values. Moreover, from the comparison with the simulations 
Table 2: Experimental cross-sections with the corresponding uncertainty ( \pm one standard

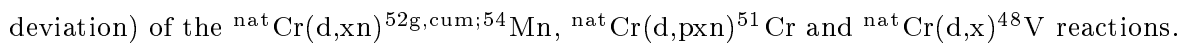

\begin{tabular}{|c|c|c|c|c|}
\hline $\begin{array}{l}\text { Energy } \\
(\mathrm{MeV})\end{array}$ & $\begin{array}{c}{ }^{52 \mathrm{~g}, \text { cum }} \mathrm{Mn} \\
(\mathrm{mb})\end{array}$ & $\begin{array}{l}{ }^{54} \mathrm{Mn} \\
(\mathrm{mb})\end{array}$ & $\begin{array}{l}{ }^{51} \mathrm{Cr} \\
(\mathrm{mb})\end{array}$ & $\begin{array}{l}{ }^{48} \mathrm{~V} \\
(\mathrm{mb})\end{array}$ \\
\hline $6.3 \pm 0.8$ & & $31.2 \pm 1.4$ & $26.8 \pm 1.2$ & $1.22 \pm 0.05$ \\
\hline $10.1 \pm 0.6$ & $39.8 \pm 1.4$ & $27.3 \pm 1.3$ & $18.0 \pm 0.8$ & $2.46 \pm 0.09$ \\
\hline $13.2 \pm 0.4$ & $104 \pm 4$ & $24.2 \pm 1.1$ & $13.4 \pm 0.6$ & $1.89 \pm 0.07$ \\
\hline $13.5 \pm 0.9$ & $105 \pm 4$ & $25.8 \pm 1.2$ & $14.2 \pm 0.7$ & $2.05 \pm 0.08$ \\
\hline $15.8 \pm 0.3$ & $139 \pm 5$ & $23.6 \pm 1.1$ & $13.2 \pm 0.6$ & $1.20 \pm 0.05$ \\
\hline $16.0 \pm 0.7$ & $139 \pm 5$ & $24.4 \pm 1.1$ & $13.4 \pm 0.6$ & $1.33 \pm 0.05$ \\
\hline $18.3 \pm 0.6$ & $155 \pm 5$ & $21 \pm 1$ & $20.2 \pm 0.9$ & $0.92 \pm 0.04$ \\
\hline $18.5 \pm 0.7$ & $171 \pm 6$ & $23.0 \pm 1.1$ & $25.0 \pm 11$ & \\
\hline $20.1 \pm 0.6$ & $165 \pm 6$ & $19.1 \pm 0.9$ & $57 \pm 1.1$ & \\
\hline $20.5 \pm 0.3$ & $158 \pm 6$ & $17.6 \pm 0.8$ & $63 \pm 3$ & $0.65 \pm 0.04$ \\
\hline $21.6 \pm 0.5$ & $163 \pm 6$ & $17.2 \pm 0.8$ & $127 \pm 6$ & \\
\hline $23.0 \pm 0.5$ & $121 \pm 4$ & $12.1 \pm 0.6$ & $127 \pm 6$ & \\
\hline $23.4 \pm 0.9$ & $107 \pm 4$ & $10.9 \pm 0.5$ & $154 \pm 7$ & \\
\hline $24.8 \pm 0.8$ & $97 \pm 3$ & $9.9 \pm 0.5$ & $224 \pm 10$ & \\
\hline $26.2 \pm 0.6$ & $87 \pm 3$ & $8.9 \pm 0.4$ & $286 \pm 13$ & $1.62 \pm 0.06$ \\
\hline $27.5 \pm 0.4$ & $68 \pm 2$ & $7.8 \pm 0.3$ & $297 \pm 14$ & $4.11 \pm 0.16$ \\
\hline
\end{tabular}




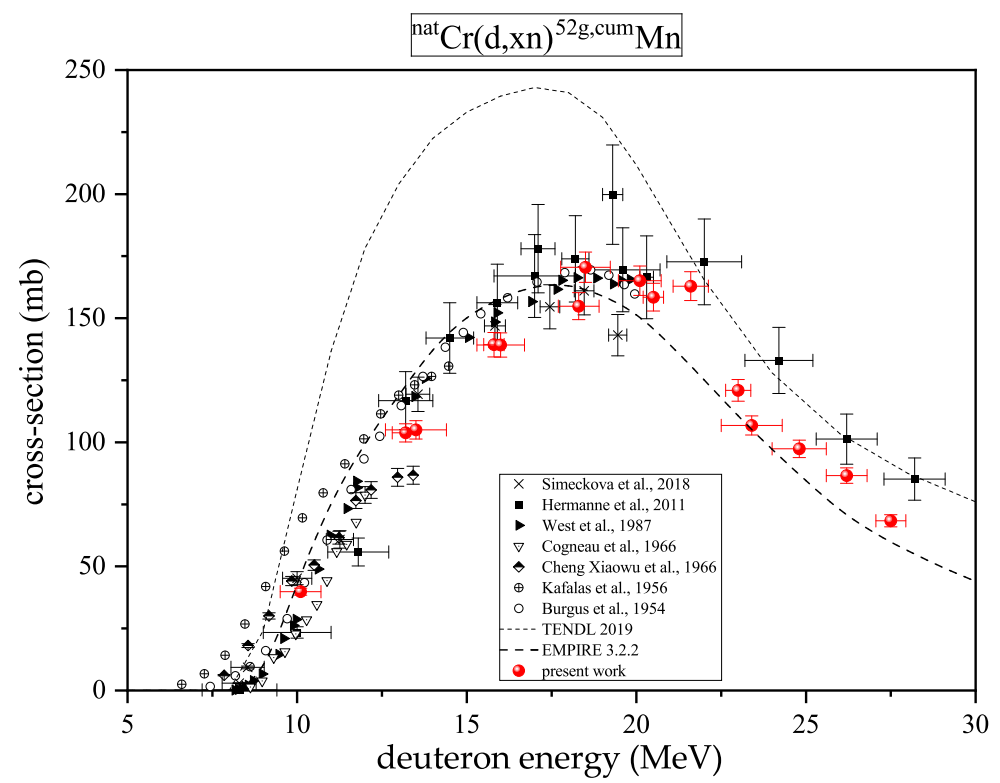

Figure 3: Excitation function for ${ }^{\text {nat }} \mathrm{Cr}(\mathrm{d}, \mathrm{xn})^{52 \mathrm{~g}, \mathrm{cum}} \mathrm{Mn}$ nuclear reactions and comparison with literature data and simulation codes.

it can be observed that TENDL 2019, dotted curve, globally overestimates the experimental data, while EMPIRE 3.2.2 very well approximates the cross section in the whole energy range under examination.

\section{2. ${ }^{n a t} \mathrm{Cr}(d, x n)^{54} \mathrm{Mn}$}

With the ${ }^{\text {nat }} \mathrm{Cr}(\mathrm{d}, \mathrm{x})$ reaction, in addition to the radionuclide of interest ${ }^{52 \mathrm{~g}} \mathrm{Mn}$, its long-life radioactive isotope ${ }^{54} \mathrm{Mn}\left(\mathrm{t}_{1 / 2}=312.3 \mathrm{~d}\right)$ is produced. The presence of ${ }^{54} \mathrm{Mn}$ decreases the radionuclidic purity of the ${ }^{52} \mathrm{Mn}$ as it is not possible to separate it chemically. Fig. 4 shows the results obtained for the crosssection of ${ }^{54} \mathrm{Mn}$. The values follow quite well the most recent published data (Simenckova et al. [16; Hermanne et al. [17]), while are in disagreement with the oldest ones of Kafalas et al. 21]. For ${ }^{54} \mathrm{Mn}$, the data of both simulations, TENDL 2019 and EMPIRE 3.2.2, describe well the trend of our experimental data, even if at higher energies EMPIRE deviates more. 


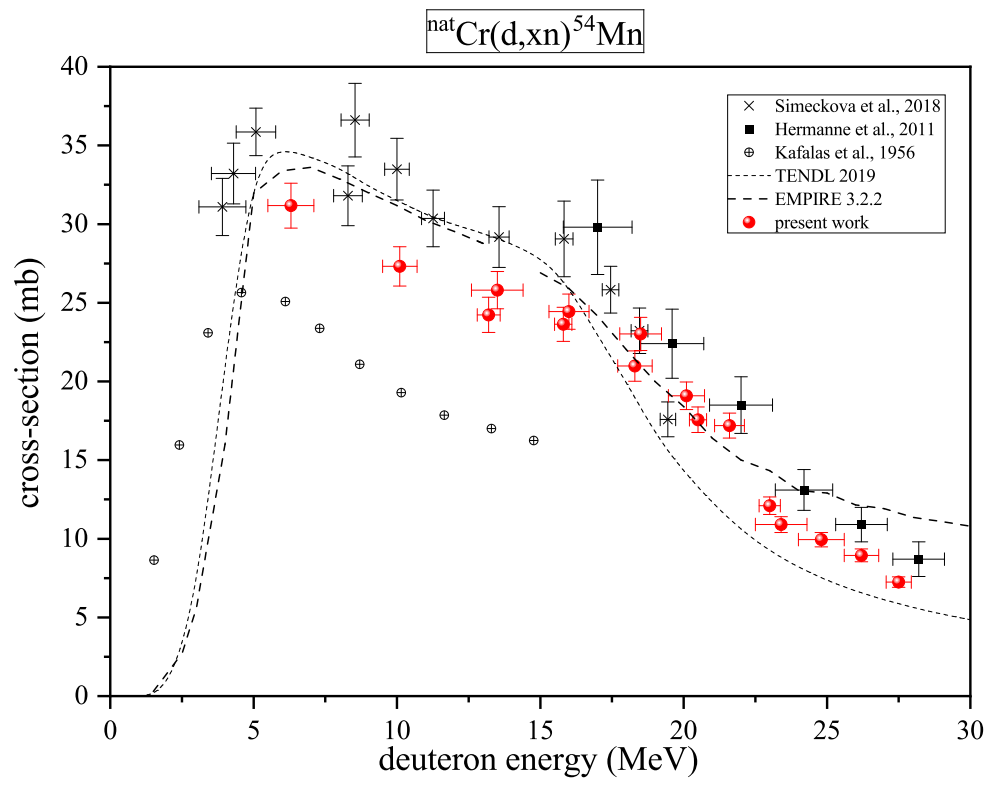

Figure 4: Excitation function for ${ }^{\text {nat }} \mathrm{Cr}(\mathrm{d}, \mathrm{xn}){ }^{54} \mathrm{Mn}$ nuclear reactions and comparison with literature data and simulation codes.

\section{3. ${ }^{n a t} \mathrm{Cr}(d, p x n)^{51} \mathrm{Cr}$ and ${ }^{\text {nat }} \mathrm{Cr}(d, x)^{48} \mathrm{~V}$}

Fig. 5 and Fig. 6 show the excitation functions obtained for ${ }^{51} \mathrm{Cr}\left(\mathrm{t}_{1 / 2}=27.702\right.$ d) and ${ }^{48} \mathrm{~V}\left(\mathrm{t}_{1 / 2}=15.9735 \mathrm{~d}\right)$. Their production does not affect the specific activity and the radionuclidic purity of ${ }^{52} \mathrm{Mn}$ as they are radiochemically separable.

However, the cross-section was also evaluated for these radionuclides and was verified the excellent agreement with the data in the literature [16, 17, 21, 22, 23, 24, 25]. In both these cases, simulations obtained with TENDL 2019 and EMPIRE 3.2.2 are in good agreement up to energies of about 20 and $24 \mathrm{MeV}$ for ${ }^{51} \mathrm{Cr}$ and ${ }^{48} \mathrm{~V}$ respectively; for higher energies TENDL deviates significantly, while EMPIRE follows better the trend of experimental data.

\subsection{Thick Target Yield for ${ }^{529, \text { cum }} \mathrm{Mn}$ and ${ }^{54} \mathrm{Mn}$ production}

Using Equation 2, the Thick Target Yields were calculated for ${ }^{52 \mathrm{~g}} \mathrm{Mn}$ (Fig. 7) and ${ }^{54} \mathrm{Mn}$ (Fig. 8), obtaining a family of curves as a function of the energy $(\mathrm{E})$ and of the energy loss in the target $(\Delta \mathrm{E})$; it is therefore possible to optimize 


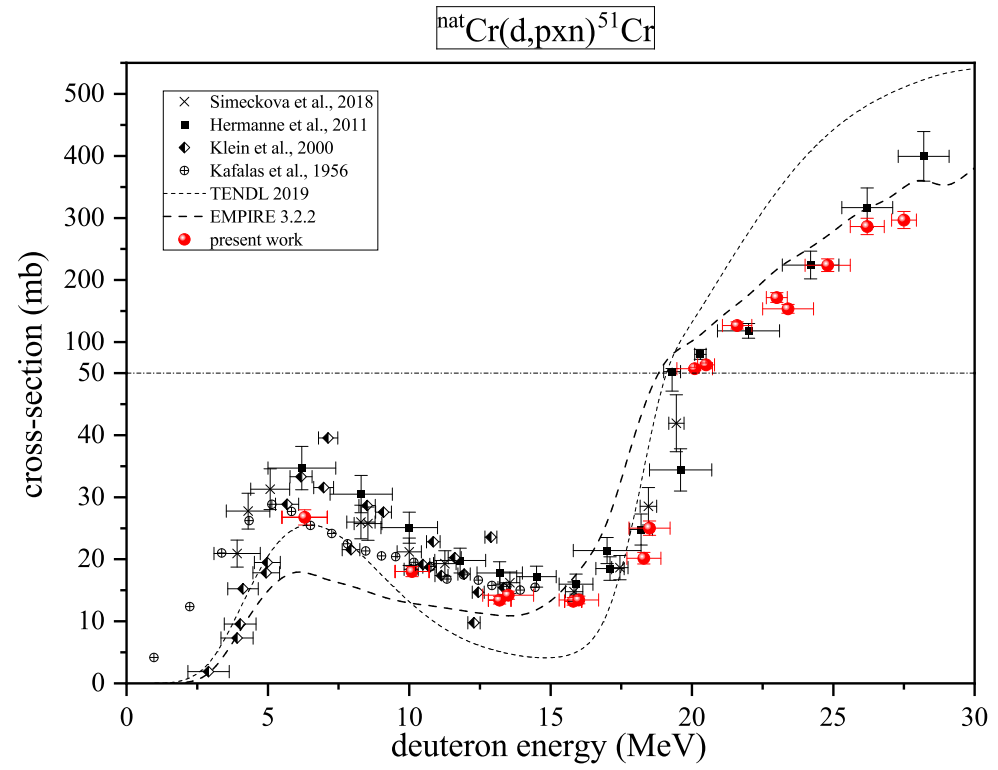

Figure 5: Excitation function for ${ }^{\text {nat }} \mathrm{Cr}(\mathrm{d}, \mathrm{pxn}){ }^{51} \mathrm{Cr}$ nuclear reactions and comparison with literature data and simulation codes.

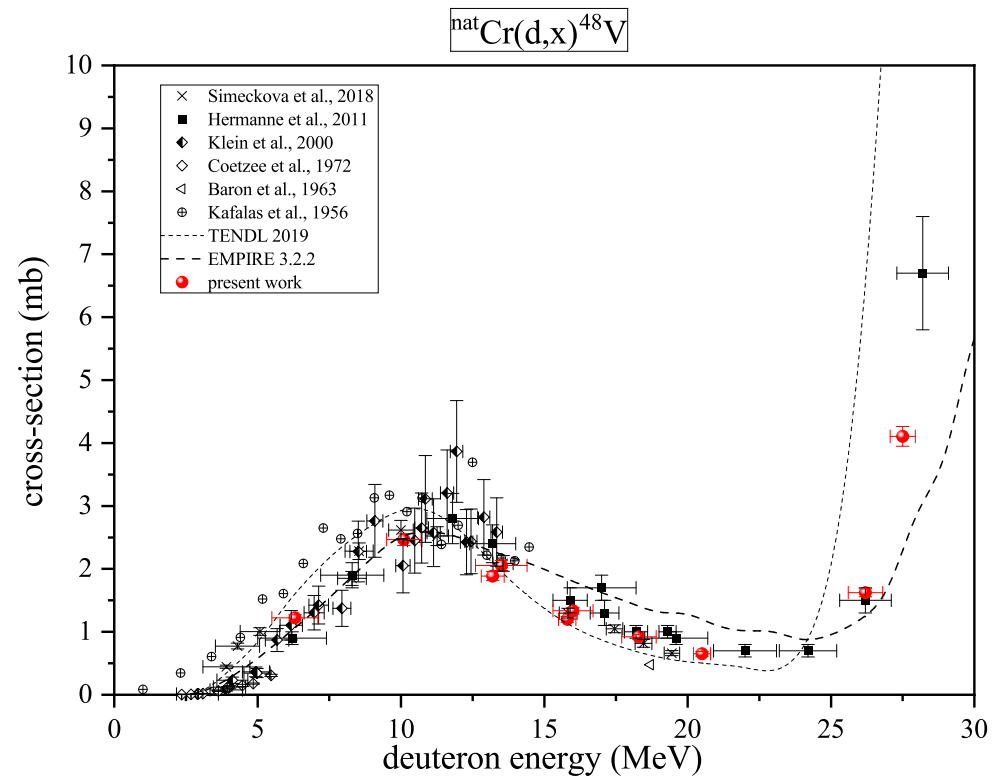

Figure 6: Excitation function for ${ }^{\text {nat }} \mathrm{Cr}(\mathrm{d}, \mathrm{xn})^{48} \mathrm{~V}$ nuclear reactions and comparison with literature data and simulation codes. 


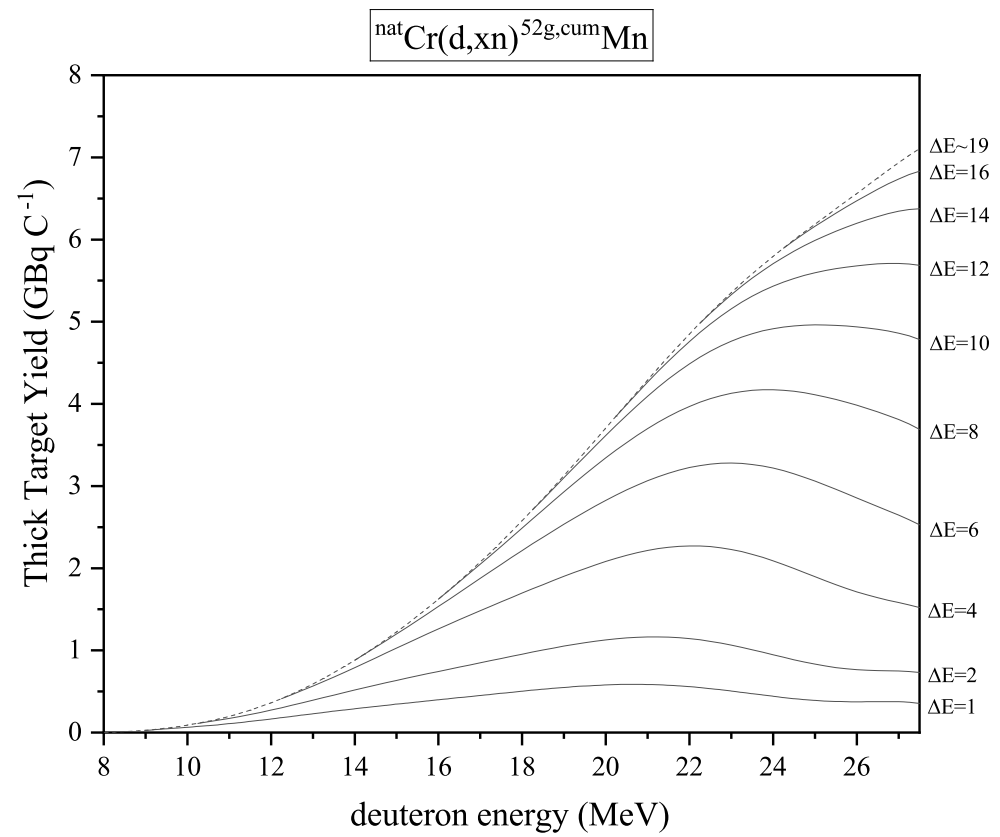

Figure 7: Thick Target Yield for ${ }^{\text {nat }} \mathrm{Cr}(\mathrm{d}, \mathrm{xn})^{52 \mathrm{~g}, \mathrm{cum}} \mathrm{Mn}$ reactions as a function of deuteron incident energy $(\mathrm{E})$ and energy loss $(\Delta \mathrm{E})$ in the target.

the beam energy and the target thickness which allow to obtain the maximum production 32 .

From Fig. 7 it was found that for $\Delta \mathrm{E}=16 \mathrm{MeV}$, Yield values are close to the total absorption curve; a higher $\Delta \mathrm{E}$ would not significantly increase the ${ }^{52 \mathrm{~g}} \mathrm{Mn}$ Yield, while there would be a more consistent increase for the production of the contaminant ${ }^{54} \mathrm{Mn}$ (Fig. 8).

Therefore it was possible to determine that with an irradiation with deuterons at $\mathrm{E}=27.5 \mathrm{MeV}$ on a chromium target with a thickness of $\sim 0.7 \mathrm{~mm}$, corresponding to an energy loss $\Delta \mathrm{E}=16 \mathrm{MeV}$, the ${ }^{52 \mathrm{~g}} \mathrm{Mn}$ can be obtained with a Yield equal to $6.8 \mathrm{GBq} \cdot \mathrm{C}^{-1}$, about 2.6 times higher than that obtained by irradiation with proton beams [8] of energy equal to $16 \mathrm{MeV}$ (Table 3), and with a RNP (Fig. 9) greater than $99 \%$ in a fairly wide time interval (up to 11 days from the EOB).

The amount of ${ }^{52 \mathrm{~g}} \mathrm{Mn}$ and ${ }^{54} \mathrm{Mn}$ that can be produced for some different 


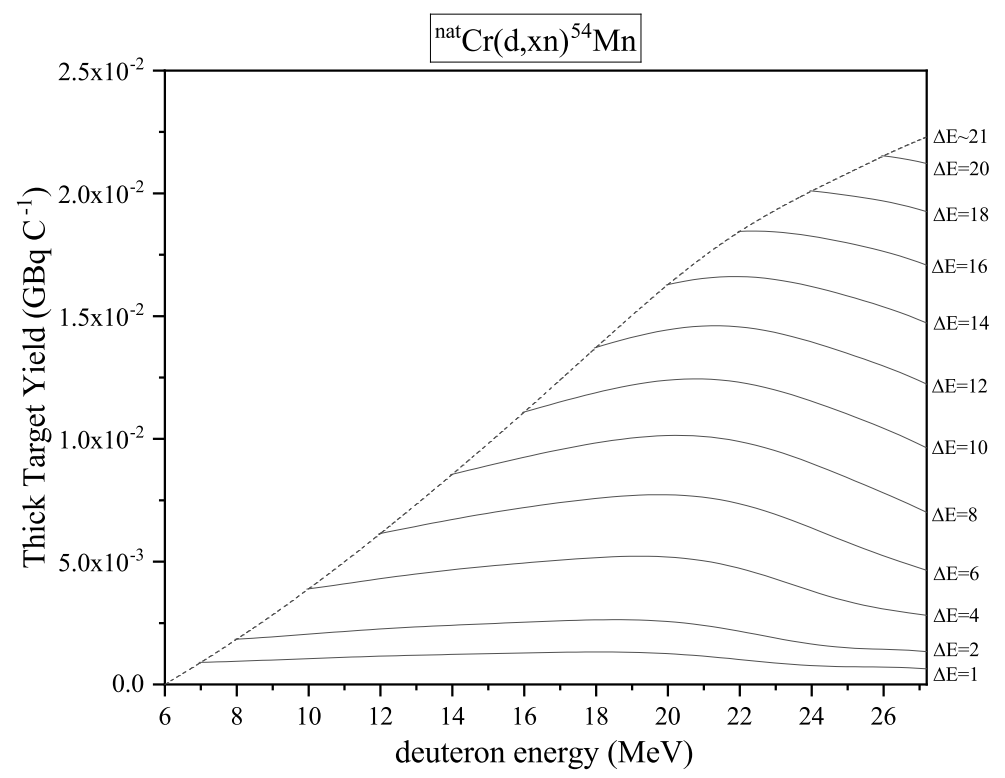

Figure 8: Thick Target Yield for ${ }^{\text {nat }} \mathrm{Cr}(\mathrm{d}, \mathrm{xn}){ }^{54} \mathrm{Mn}$ reactions as a function of deuteron incident energy $(\mathrm{E})$ and energy loss $(\Delta \mathrm{E})$ in the target.

Table 3: Comparison between the TTY and RNP for the production with deuteron and proton irradiations

\begin{tabular}{|c|c|c|c|}
\hline & ${ }^{\text {nat }} \mathrm{Cr}(\mathrm{d}, \mathrm{xn})^{52 \mathrm{~g}} \mathrm{Mn}$ & \multicolumn{2}{|c|}{${ }^{\text {nat }} \mathrm{Cr}(\mathrm{p}, \mathrm{xn})^{52 \mathrm{~g}} \mathrm{Mn}[8,15$} \\
\hline $\mathbf{E}_{\text {beam }}$ & $27.5 \mathrm{MeV}$ & $16 \mathrm{MeV}$ & $17 \mathrm{MeV}$ \\
\hline Target thickness & $0.7 \mathrm{~mm}(\Delta \mathrm{E}=16 \mathrm{MeV})$ & $0.4 \mathrm{~mm}(\Delta \mathrm{E}=6.6 \mathrm{MeV})$ & $0.5 \mathrm{~mm}(\Delta \mathrm{E}=9 \mathrm{MeV})$ \\
\hline TTY & $6.8 \mathrm{GBq} \cdot \mathrm{C}^{-1}$ & $2.63 \pm 0.22 \mathrm{GBq} \cdot \mathrm{C}^{-1}$ & $3.89 \mathrm{GBq} \cdot \mathrm{C}^{-1}$ \\
\hline RNP & $99.75 \%$ & $99.55 \%$ & - \\
\hline
\end{tabular}




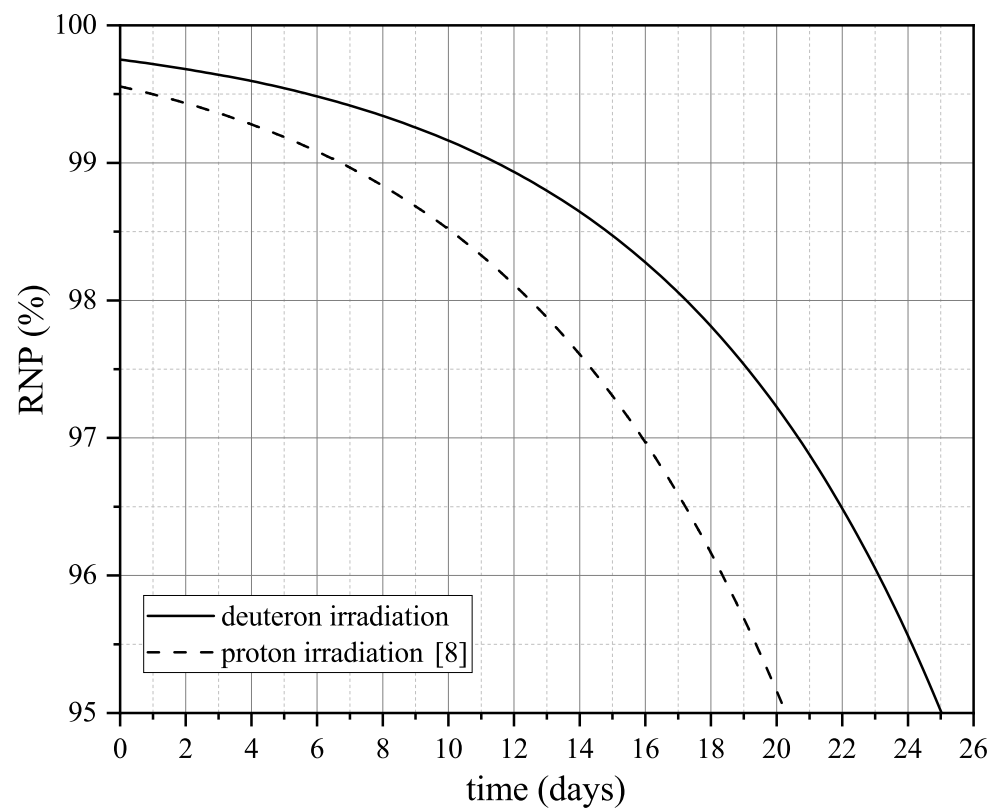

Figure 9: Comparison of RNP as a function of time from the EOB for irradiation by protons and deuterons.

irradiation times is reported in Table 4 the quantity, for both the radionuclides, is a linear function of irradiation time for $\mathrm{t}_{\mathrm{irr}}<20 \mathrm{~h}$ since $\lambda_{\mathrm{Mn}-52 \mathrm{~g}, 54} \cdot \mathrm{t}_{\mathrm{irr}} \ll 1$.

\section{Conclusions}

In this work the cross-sections of ${ }^{\text {nat }} \mathrm{Cr}(\mathrm{d}, \mathrm{x})$ reactions were studied in order to optimize the production of the radionuclide ${ }^{52 \mathrm{~g}} \mathrm{Mn}$, whose use in $\mathrm{Nu}$ clear Medicine is very promising. The energy range examined is from $8 \mathrm{MeV}$,

Table 4: Amount of ${ }^{52 \mathrm{~g}} \mathrm{Mn}$ and ${ }^{54} \mathrm{Mn}$ that can be produced at different irradiation times

$1 \mathbf{h}$

\begin{tabular}{cccc}
\hline${ }^{52 g} \mathrm{Mn}$ & $0.024 \mathrm{GBq} \cdot \mu \mathrm{A}^{-1}$ & $0.097 \mathrm{GBq} \cdot \mu \mathrm{A}^{-1}$ & $0.19 \mathrm{GBq} \cdot \mu \mathrm{A}^{-1}$ \\
${ }^{54} \mathrm{Mn}$ & $6.1 \cdot 10^{-5} \mathrm{GBq} \cdot \mu \mathrm{A}^{-1}$ & $2.5 \cdot 10^{-4} \mathrm{GBq} \cdot \mu \mathrm{A}^{-1}$ & $4.9 \cdot 10^{-4} \mathrm{GBq} \cdot \mu \mathrm{A}^{-1}$ \\
\hline
\end{tabular}



ton beams in terms of higher yield and higher radionuclidic purity; the main criticality is related to the small number of cyclotrons that can accelerate deuterons with appropriate energies and intensities.

\section{Acknowledgements}

This work was funded in the framework of the research project METRICS by INFN (Italian National Institute of Nuclear Physics, CSN5).

The cyclotron Arronax is supported by the European Union. This work has been, in part, supported by a grant from the French National Agency for Research called "Investissements d'Avenir", Equipex Arronax-Plus noANR-11-

240 EQPX-0004, Labex IRON noANR-11-LABX-18-01 and ISITE NEXT no. ANR16-IDEX-0007.

\section{References}

[1] R. B. Firestone, C. M. Baglin, S. Y. F. Chu, Table of Isotopes: 1999 Update with CD-ROM, 1999 Update, 8th Edition, Wiley-Interscience, 1999.

[2] C. Le Loirec, C. Champion, Track structure simulation for positron emitters of physical interest. Part II: The case of the radiometals, Nuclear In- 
struments and Methods in Physics Research A 582 (2) (2007) 654-664. doi:10.1016/j.nima.2007.08.179

[3] C. Le Loirec, C. Champion, Track structure simulation for positron emitters of medical interest. Part I: The case of the allowed decay isotopes, Nuclear Instruments and Methods in Physics Research A 582 (2) (2007) 644-653. doi:10.1016/j.nima.2007.08.159.

[4] M. Pagani, S. Stone-Elander, S. A. Larsson, Alternative positron emisphysical properties on image quality and potential clinical applications, European Journal of Nuclear Medicine 24 (10) (1997) 1301-1327. doi: $10.1007 / \mathrm{s} 002590050156$.

[5] G. J. Topping, P. Schaffer, C. Hoehr, T. J. Ruth, V. Sossi, Manganese52 positron emission tomography tracer characterization and initial results in phantoms and in vivo, Medical Physics 40 (4) (2013) 042502. doi: $10.1118 / 1.4793756$

[6] D. Chauncey, H. Schelbert, S. Halpern, F. Delano, M. McKegney, W. Ashburn, P. Hagan, Tissue distribution studies with radioactive manganese: a potential agent for myocardial imaging, Journal of nuclear medicine: official publication, Society of Nuclear Medicine 18 (9) (1977) 933-936.

[7] P. F. Antkowiak, B. K. Stevens, C. S. Nunemaker, M. McDuffie, F. H. Epstein, Manganese-enhanced magnetic resonance imaging detects declining pancreatic $\beta$-cell mass in a cyclophosphamide-accelerated mouse model of type 1 diabetes, Diabetes 62 (1) (2013) 44-48. doi:10.2337/db12-0153.

[8] C. M. Lewis, S. A. Graves, R. Hernandez, H. F. Valdovinos, T. E. Barnhart, W. Cai, M. E. Meyerand, R. J. Nickles, M. Suzuki, ${ }^{52} \mathrm{Mn}$ production for PET/MRI tracking of human stem cells expressing divalent metal transporter 1 (DMT1), Theranostics 5 (2015) 227-239. doi:10.7150/thno. 10185 
[9] S. A. Graves, R. Hernandez, J. Fonslet, C. G. England, H. F. Valdovinos, P. A. Ellison, T. E. Barnhart, D. R. Elema, C. P. Theuer, W. Cai, R. J. Nickles, G. W. Severin, Novel preparation methods of ${ }^{52} \mathrm{Mn}$ for ImmunoPET imaging, Bioconjugate Chemistry 26 (10) (2015) 2118-2124, pMID: 26317429. doi:10.1021/acs.bioconjchem.5b00414.

[10] G. Saar, C. M. Millo, L. P. Szajek, J. Bacon, P. Herscovitch, A. P. Koretsky, Anatomy, functionality, and neuronal connectivity with manganese radiotracers for positron emission tomography, Molecular Imaging and Biology 20 (4) (2018) 562-574. doi:10.1007/s11307-018-1162-6. and opportunities for nanomedicine in the management of atherosclerosis, (1) Nature Reviews Drug Discovery 10 (11) (2011) 835-852. doi:10.1038/ nrd3578,

[12] A. L. Wooten, Cyclotron production and biomedical imaging applications of the PET isotope manganese-52, phdthesis, WASHINGTON UNIVERSITY IN ST. LOUIS School of Engineering \& Applied SciencesDepartment of Biomedical Engineering, engineering and Applied Science Theses \& Dissertations. 174. (2016).

[13] M. Buchholz, I. Spahn, B. Scholten, H. Coenen H., Cross-section mea295 surements for the formation of manganese-52 and its isolation with a nonhazardous eluent, Radiochimca Acta 101 (8) (2013) 491.

[14] A. L. Wooten, B. C. Lewis, S. E. Lapi, Cross-sections for (p,x) reactions on natural chromium for the production of ${ }^{52,52 m, 54} \mathrm{Mn}$ radioisotopes, Applied

1. Radiation and Isotopes 96 (2015) 154-161. doi:10.1016/j.apradiso. 2014.12.001.

[15] S. M. Qaim, Nuclear data for production and medical application of radionuclides: Present status and future needs, Nuclear Medicine and Biology 44 (2017) 31-49. doi:10.1016/j.nucmedbio.2016.08.016. 
[16] E. Šimečková, M. Avrigeanu, U. Fischer, J. Mrázek, J. Novak, M. Štefánik, C. Costache, V. Avrigeanu, Consistent account of deuteron-induced reactions on ${ }^{\text {nat }} \mathrm{Cr}$ up to $60 \mathrm{MeV}$, Phys. Rev. C 98 (2018) 034606. doi: 10.1103/PhysRevC.98.034606

[17] A. Hermanne, R. A. Rebeles, F. Tárkányi, S. Takács, M. Takács, A. Ignatyuk, Cross sections of deuteron induced reactions on ${ }^{\text {nat }} \mathrm{Cr}$ up to 50 $\mathrm{MeV}$ : Experiments and comparison with theoretical codes, Nuclear Instruments and Methods in Physics Research Section B: Beam Interactions with Materials and Atoms 269 (21) (2011) 2563-2571. doi:10.1016/j.nimb. 2011.07 .008 .

[18] H. I. West, R. G. Lanier, M. G. Mustafa, ${ }^{52} \mathrm{Cr}(\mathrm{p}, \mathrm{n})^{52} \mathrm{Mn}^{g, m}$ and 315 ${ }^{52} \mathrm{Cr}(\mathrm{d}, 2 \mathrm{n}){ }^{52} \mathrm{Mn}^{g, m}$ excitation functions, Phys. Rev. C 35 (1987) 2067-2076. doi:10.1103/PhysRevC.35.2067.

[19] M. Cogneau, L. Gilly, J. Cara, Absolute cross sections and excitation functions for deuteron induced reactions on chromium between 2 and $12 \mathrm{MeV}$,

1. Nuclear Physics 79 (1) (1966) 203-208. doi:10.1016/0029-5582(66) $320 \quad 90403-2$.

[20] C. Xiaowu, W. Zhenxia, W. Zhenjie, Y. Jinging, Some measurements of deuteron induced excitation function at $13 \mathrm{MeV}$, Acta Physica Sinica 22 (1966) 250-252.

[21] P. Kafalas, J. W. Irvine, Nuclear excitation functions and thick target 325 ㅁ yields: $(\mathrm{Cr}+d)$, Phys. Rev. 104 (1956) 703-705. doi:10.1103/PhysRev. 104.703

[22] W. H. Burgus, G. A. Cowan, J. W. Hadley, W. Hess, T. Shull, M. L. Stevenson, H. F. York, Cross sections for the reactions $\mathrm{Ti}^{48}(\mathrm{~d}, 2 \mathrm{n}) \mathrm{V}^{48}$; 口 $\mathrm{Cr}^{52}(\mathrm{~d}, 2 \mathrm{n}) \mathrm{Mn}^{52}$; and $\mathrm{Fe}^{56}(\mathrm{~d}, 2 \mathrm{n}) \mathrm{Co}^{56}$, Phys. Rev. 95 (1954) 750-751. doi: 10.1103/PhysRev.95.750. 
[23] A. Klein, F. Rösch, M. Qaim Syed, Investigation of ${ }^{50} \mathrm{Cr}(\mathrm{d}, \mathrm{n})^{51} \mathrm{Mn}$ and ${ }^{n a t} \mathrm{Cr}(\mathrm{p}, \mathrm{x})^{51} \mathrm{Mn}$ processes with respect to the production of the positron emitter 51mn, Radiochimica Acta 88 (5) (2000) 253.

[24] P. P. Coetzee, M. A. X. Peisach, Activation cross sections for deuteroninduced reactions on some elements of the first transition series, up to 5.5 $\mathrm{MeV}(1972)$.

[25] N. Baron, B. L. Cohen, Activation cross-section survey of deuteron-induced reactions, Phys. Rev. 129 (1963) 2636-2642. doi:10.1103/PhysRev.129. 2636.

[26] E. Mace, S. Auduc, C. Huet, S. Girault, F. Poirier, J. L. Delvaux, F. Haddad, The C70 ARRONAX and Beam Lines Status, Conf. Proc. C110904 (2011) 2661-2663.

[27] A. Hermanne, A. Ignatyuk, R. Capote, B. Carlson, J. Engle, M. Kellett, T. Kibédi, G. Kim, F. Kondev, M. Hussain, O. Lebeda, A. Luca, Y. Nagai, H. Naik, A. Nichols, F. Nortier, S. Suryanarayana, S. Takács, F. Tárkányi, M. Verpelli, Reference cross sections for charged-particle monitor reactions, Nuclear Data Sheets 148 (2018) 338-382, special Issue on Nuclear Reaction Data. doi:10.1016/j.nds.2018.02.009.

[28] M. Wang, G. Audi, F. G. Kondev, W. Huang, S. Naimi, X. Xu, The AME2016 atomic mass evaluation (II). tables, graphs and references, Chinese Physics C 41 (3) (2017) 030003. doi:10.1088/1674-1137/41/3/ 030003 .

URL https: //doi.org/10.1088\%2F1674-1137\%2F41\%2F3\%2F030003

[29] S. Manenti, M. d. C. Alí Santoro, G. Cotogno, C. Duchemin, F. Had355 dad, U. Holzwarth, F. Groppi, Excitation function and yield for the ${ }^{103} \mathrm{Rh}(\mathrm{d}, 2 \mathrm{n}){ }^{103} \mathrm{Pd}$ nuclear reaction: Optimization of the production of 口 palladium-103, Nuclear Medicine and Biology 49 (2017) 30-37. doi: $10.1016 / j$. nucmedbio.2017.02.005 
[30] A. Koning, D. Rochman, J.-C. Sublet, N. Dzysiuk, M. Fleming, S. van der

360 Marck, TENDL: Complete nuclear data library for innovative nuclear science and technology, Nuclear Data Sheets 155 (2019) 1-55, special Issue on Nuclear Reaction Data. doi:10.1016/j.nds.2019.01.002.

[31] M. Herman, R. Capote, B. Carlson, P. Obložinský, M. Sin, A. Trkov, H. Wienke, V. Zerkin, EMPIRE: Nuclear reaction model code system for 365 data evaluation, Nucl. Data Sheets 108 (2007) 2655. doi:10.1016/j.nds. 2007.11 .003 .

[32] M. Bonardi, Proceedings of the IAEA Consultants' Meeting on Data Requirements for Medical Radioisotope Production, Tokyo, Japan, 20-24 April 1987, Vol. INDC(NDS)-195/GZ, IAEA, 1987, Ch. The contribution

370 to nuclear data for biomedical radioisotope production from the Milan $\mathrm{Cy}$ clotron Laboratory, pp. $98-112$. 